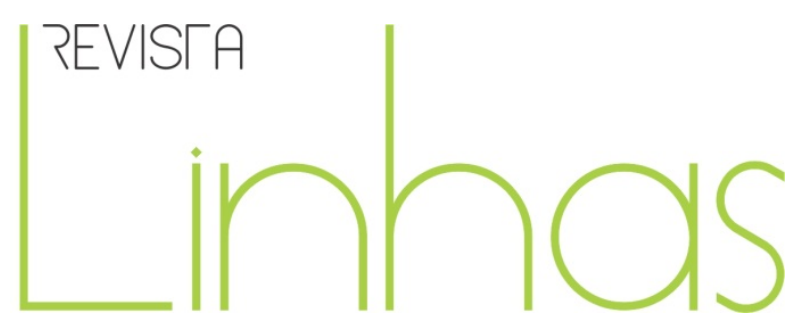

\title{
Responsabilidade socioambiental como estratégia de subjetivação dos sujeitos do ensino superior
}

\begin{abstract}
Resumo
Em tempos de globalização, as políticas econômicas neoliberais tornaram-se hegemônicas e, com isso, sua ideologia. Por conseguinte, essa forma de pensar e organizar a sociedade espraiouse pelo sistema educacional. O que se vê é a presença de discursos oriundos da cultura empresarial que transformam alunos e famílias em clientes, minimizam a ação do Estado nesse setor e atribuem aos indivíduos toda a responsabilidade pelos seus investimentos, resultados e pela proteção da vida, baseando-se na crença de que cada um poderá fazer a diferença num mundo de predadores. $\mathrm{O}$ presente artigo relata uma pesquisa que investigou os modos de subjetivação das políticas neoliberais presentes no interior de um curso de Licenciatura em Educação Física de uma Instituição de Ensino Superior privada. Dentre as práticas localizadas, foi destacada a presença de ações e discursos que enaltecem aqueles que assumem uma posição de sujeito comprometida com a responsabilidade socioambiental. Ações que misturam intenções solidárias com interesses mercadológicos.
\end{abstract}

Palavras-chave: Ensino Superior - Educação Física (Ensino Superior); Currículo; Proteção Ambiental.

\section{Mario Luiz Ferrari Nunes}

Doutor em Educação pela

Faculdade de Educação da Universidade de São Paulo - USP Brasil

mario.nunes@usp.br

\section{Marcos Garcia Neira}

Doutor em Educação pela

Faculdade de Educação da Universidade de São Paulo - USP Brasil mgneira@usp.br

\footnotetext{
Para citar este artigo:

NUNES, Mario Luiz Ferrari; NEIRA, Marcos Garcia. Responsabilidade socioambiental como estratégia de subjetivação dos sujeitos do ensino superior. Revista Linhas. Florianópolis, v. 15, n. 29, p. 463-480, jul./dez. 2014.
}

DOI: $10.5965 / 1984723815292014463$

http://dx.doi.org/10.5965/1984723815292014463 


\title{
Environmental responsibility as strategy to the individual subjectivity in higher education
}

\begin{abstract}
In times of globalization, neoliberal economic policies have become hegemonic and with that, their ideology. Consequently, this way of thinking and organizing society spilled over the educational system. What you see is the presence of a discourse from business culture that changes families and students into customers, minimize state action in this area, and delegate to the individuals the whole responsibility for their investments, results and the protection of life based on the belief that everyone can make a difference in a world of predators. This article reports a study that investigated the modes of subjectivity present in neoliberal policies within a Degree in Physical Education from a private institution of higher education. Among the practices found, it was highlighted the presence of actions and speeches that exalt those who assume a individual position committed to environmental responsibility. Actions that mix supportive intentions with market interests.
\end{abstract}

Keywords: Higher Education - Physical Education (Higher Education); Curriculum; Environmental Protection. 


\section{Introdução}

Os dias de hoje podem ser caracterizados de muitas maneiras, muito embora todas decorram da crescente onda da globalização. A tentativa de unificação do mundo, diversos fenômenos econômicos, alterações geopolíticas e a infindável produção de inovações tecnológicas fazem com que surjam novos padrões de comportamento, modificando as possibilidades de quem nós deveríamos nos tornar (BALL, 2006). Com isso, novas práticas culturais eclodem a todo instante e por todos os lados e, como consequência, criam-se novas estratégias de regulação das populações. Como afirma Lipovetsky (2012), a globalização é uma manifestação cultural.

Dentre os efeitos da globalização encontra-se a difusão planetária de corporações transnacionais que assumem posições de destaque na economia e no controle do capital. Elas enfraquecem o ideário de Estado-nação e abalam a capacidade dos países mais antigos e tradicionais, além das sociedades emergentes, estabelecerem seus modos de ser ou controlar seu ritmo de desenvolvimento (HALL, 1997). À globalização pode-se associar a consolidação do neoliberalismo como a ideologia hegemônica destes tempos. O neoliberalismo trouxe o pensamento econômico para as políticas sociais e consolidou nesse cenário termos referentes ao mercado como privatização, escolha do cliente e transmissão de práticas de assistência social (POPKEWITZ, 2004).

Veiga-Neto (2000) explica que o neoliberalismo não diminuiu a função reguladora do Estado, como é corrente afirmar. Ele criou uma série de aparatos a fim de regular as atividades privadas, que antes eram de responsabilidade estatal. Isso favoreceu as parcerias público-privadas e a criação de entidades não governamentais para prestação de serviços públicos. Para o autor, o neoliberalismo pode ser entendido como um conjunto de técnicas e saberes que favorecem tanto a expansão das formas do capitalismo contemporâneo quanto a concepção moderna do Estado como um organismo administrativo. No atual momento sócio histórico, esse conjunto faz com que o Estado siga a lógica do empreendedorismo, transformando-se em uma grande empresa. Privatizam-se as estatais lucrativas enquanto as atividades não lucrativas como 
a saúde, educação e segurança são atreladas aos padrões do mercado. O resultado dessa articulação é que as atividades estatais não lucrativas são direcionadas aos estratos sociais desprovidos, aqueles que não podem gerar acúmulo de capital ao empreendedor. O que pode incorrer em lucro destina-se a quem pode pagar pelo "serviço" - o cliente (VEIGA-NETO, 2000). Por outro lado, o Estado amplia seus planos assistenciais aos ricos, salvaguardando seus interesses, mantendo sua relação histórica de simbiose (BAUMAN, 2010). A relação entre Estado e o mercado faz da comunidade (no sentido de Rousseau) um objeto de regulação, tornando cada vez mais difícil realizar qualquer debate que não esteja sob os enfoques do plano econômico.

O Estado como regulador do sistema social abriu as portas para a transferência dos serviços de provisão da população para entidades assistencialistas e o trabalho voluntário. Não que isso seja uma novidade em se tratando de Brasil, afinal, vivenciamos um Estado clientelista e paternalista. O neoliberalismo brasileiro não pode ser associado simplesmente à retirada de conquistas sociais e ao desmonte do Estado. O que temos é a afirmação das prerrogativas de concepção neoliberal nas quais o Estado do bem-estar é dispendioso, desvia recursos públicos, desequilibra o orçamento e provoca déficits públicos. Uma série de atos que têm por resultado a geração da inflação e do desemprego, criando e ampliando a crise social.

Nesse raciocínio, o Estado não deve conceder recursos para as políticas sociais. Os insumos devem ser direcionados apenas para os setores produtivos, em benefício daqueles que alimentam o mercado. Como resultado dessa matemática social, quem produz não pode arcar com o ônus dos sujeitos improdutivos. A vida deles ficará a cargo das ações beneficentes dos homens de boa-vontade com seus atos benevolentes e da crença que a produtividade do mercado gerará excedentes financeiros que poderão ser designados para cuidar dos improdutivos (BURBULES; TORRES, 2004).

Nessa contingência, a cultura brasileira assistencialista e de benemerência se articula com a atual cultura neoliberal de autoajuda, ajuda solidária e autoculpa pelas mazelas sociais que reverberam no espaço público por meio de editorias, ficções literárias e fílmicas, campanhas midiáticas etc. Por negar o espaço público em detrimento do privado, o neoliberalismo reforça a tradição populista que, associada aos discursos 
apaziguadores do Terceiro Setor e da comunidade solidária, transfere para os voluntários das ações empresariais e da sociedade civil as funções do Estado. Cabe aqui, também, enfatizar o efeito dos discursos que reforçam o protagonismo social: fazer a diferença. Se cada um fizer a sua parte não há necessidade do Estado desviar seus recursos para os mais necessitados.

Diante dessas mudanças, Ball (2002) atenta para as novas formas de regulação sobre os modos de ser que o Estado, em sua reorganização, adquire para controlar as capacidades e qualidades dos sujeitos da educação em todos os níveis. Denuncia a pretensão de transformar a todos em sujeitos capazes de incorporar uma empresa do self, tornando-os competitivos uns com os outros e, consequentemente, possibilitando o aumento de produtividade.

Ball (2004) afirma que não há como negar a existência de novas formas de controle e regulação da vida privada, que operam a construção de certo tipo de sujeito. Essa reorganização do Estado parece facilitar a consolidação de uma nova concepção de cidadania com habilidades e competências que interessam à nova ordem da economia global. Para o pedagogo inglês, a versão neoliberal da globalização incide em uma agenda educacional que impõe certas políticas de avaliação, financiamento, formação de professores, diretrizes curriculares e metodologias. O que está em jogo parece ser a constituição das identidades ideais para compor o quadro social globalizado.

Os mecanismos empregados no processo de constituição identitária têm especial guarida no Ensino Superior. É interessante notar dentre as várias facetas do almejado cidadão global a instauração da lógica da responsabilidade socioambiental. Produto das tecnologias de subjetivação do ideário neoliberal que introduz a ambiguidade característica destes tempos. Afinal, se, de um lado, a produção que sustenta o consumo, ancorada pela articulação entre a ciência e o capitalismo, leva-nos a catástrofes ambientais, de outro, desenvolvem-se estudos e manifestações em busca da construção de um mundo melhor e sustentável. Se, de um lado, muitos sujeitos da sociedade atual são escarificados com as marcas do consumismo e do individualismo, de outro, cria-se um diferencial para amenizar ou tentar "deixar de lado" esse efeito muitas vezes visto como nefasto e causador de estragos socioambientais. Na onda atual do consumo, os sujeitos 
da educação do Ensino Superior e as IES acompanham tanto a moda verde como a moda do trabalho voluntário e com isso se autoproclamam protetoras do meio ambiente e responsáveis sociais. Todos querendo fazer acreditar que praticam ações na direção de um mundo melhor.

\section{As estratégias}

Impelidas pelo atual cenário da globalização, pela LDB 9.394 e pelas políticas públicas de inclusão social, as IES abriram as portas para parcela da população outrora alijada desse nível de ensino e conclamam a valorização da diversidade cultural. Em tal cenário, a instituição na qual a pesquisa foi realizada investe de forma maciça no discurso da responsabilidade socioambiental. O que se nota é apelo a formas variadas de celebrar a presença de grupos culturais distintos em seu interior e, com eles, exaltar o cuidado com o próximo (que está distante) e do meio em que se vive como a atitude louvável destes tempos. Nesse jogo, se instaura o embrião de mais uma identidade para os estudantes do Ensino Superior brasileiro: o sujeito responsável socioambiental. Talvez, uma tentativa de fixar um aspecto romântico às condições de competição e exacerbação do individualismo e do capitalismo parasitário que nos fala Bauman (2010).

No caso investigado, antes da sua homologação como Centro Universitário, ocorrida em 2008, a instituição mantinha alguns projetos sociais realizados, em sua maioria, pelos cursos de Enfermagem e Fisioterapia. Com o novo status institucional, os vários setores passaram a participar ativamente da comunidade educativa, promovendo eventos largamente divulgados. Também foi estruturado um programa de extensão (cursos e serviços) envolvendo 300 parcerias formalmente constituídas que abarcam os estágios supervisionados e uma política de financiamento dos estudos com valores acordados entre a instituição e empresas dos setores privado e público, além de entidades religiosas. O programa também promove 60 projetos sociais de intervenção direta em diversas comunidades. Nos últimos anos, implementou 430 projetos comunitários e 15.000 atendimentos à população realizados pelos estudantes dos cursos da área da Saúde. 
O Departamento de Extensão e Assuntos Comunitários (DEAC) articula o ensino, a pesquisa e as comunidades internas e externas, por meio de atividades experienciais, oficinas sob a responsabilidade de discentes ou docentes, projetos sociais, culturais e estágios internos e externos. O DEAC implementa projetos que promovem práticas educativas e ações comunitárias, principalmente em comunidades denominadas carentes. Nelas, os alunos e alunas de alguns cursos atuam em ações múltiplas e interdisciplinares.

Há alguns anos, com participação de coordenadores, professores, alunos e representantes da comunidade, o departamento instaurou uma comissão interna de meio-ambiente e responsabilidade social. Tem por objetivo realizar atividades de conscientização da comunidade, no seu âmbito interno e externo, por meio de palestras de orientação acerca da necessidade de cuidar do planeta e meio ambiente. Dentre as atividades destacam-se:

- A instalação de 3 conjuntos de coletores de lixo seletivo;

- O recolhimento de papel e a arrecadação de latas de alumínio e garrafas pet destinadas para a reciclagem;

- A coleta de pilhas e baterias de celular para descarte ambientalmente correto;

- Palestra para todos os alunos proferida pelo então Deputado Federal Ricardo Trípoli no teatro da Universidade;

- A instalação na sala dos professores do campus de coletor de copos descartáveis; - A criação de boletim informativo da comissão a fim de manter comunicação com a comunidade interna da instituição $e$ interagir com as comunidades externas para expandir essas ações e informações;

Fonte: Portal da internet

A responsabilidade com o meio ambiente funciona dentro do jogo de trocas de mercado sem deixar de lado as necessárias formas de controle para regular as ações dos sujeitos. Isso pode ser observado na mensagem eletrônica a seguir, dirigida aos alunos e docentes: 
Tem sido comum, nos últimos semestres, um número expressivo de alunos converterem em Horas de Atividades Complementares a reciclagem de latas, garrafas pets e óleo de cozinha.

Esses materiais eram entregues de segunda a sábado, no horário das $8 \mathrm{~h}$ às $23 \mathrm{~h}$, causando enormes problemas para todos nós, inclusive péssimas condições de limpeza e higiene ao campus pelo transporte e manipulação dos mesmos nas diversas instalações do [...] e, em alguns casos, até mesmo em sala de aula.

Outro detalhe, não há como manter 3 ou 4 funcionários, em tempo integral, para esse atendimento de acordo com a disponibilidade de cada aluno.

Isso posto, decidimos e estaremos comunicando a todos os alunos que esses materiais, doravante, serão recepcionados em nosso campus APENAS E EXCLUSIVAMENTE EM ALGUNS SÁBADOS PREVIAMENTE DETERMINADOS POR NÓS.

Nesses dias designaremos local e funcionários para recepção dos produtos de maneira ordeira e higiênica, sem prejuízo as demais atividades da Instituição.

Por cópia, damos ciência à Ouvidoria, pois certamente alguns alunos reclamarão da entrega ocorrer apenas aos sábados, mas, temos como argumentos:

- o aluno não é obrigado a entregar tais produtos para cumprir suas Horas Complementares Comunitárias; no Comunicado que enviaremos a todos daremos sugestões alternativas;

- a atividade é comunitária, portanto, o fato de o alunos vir ao campus em dia alternativo é sinal de seu comprometimento com as comunidades carentes ou com as questões de autosustentabilidade.

Fonte: Mensagem eletrônica encaminhada à comunidade educativa

Além do programa de responsabilidade ambiental, a instituição dissemina outro discurso contemporâneo: a responsabilidade social. E assim como a ação anterior, faz da troca de interesses sua locomotiva. 


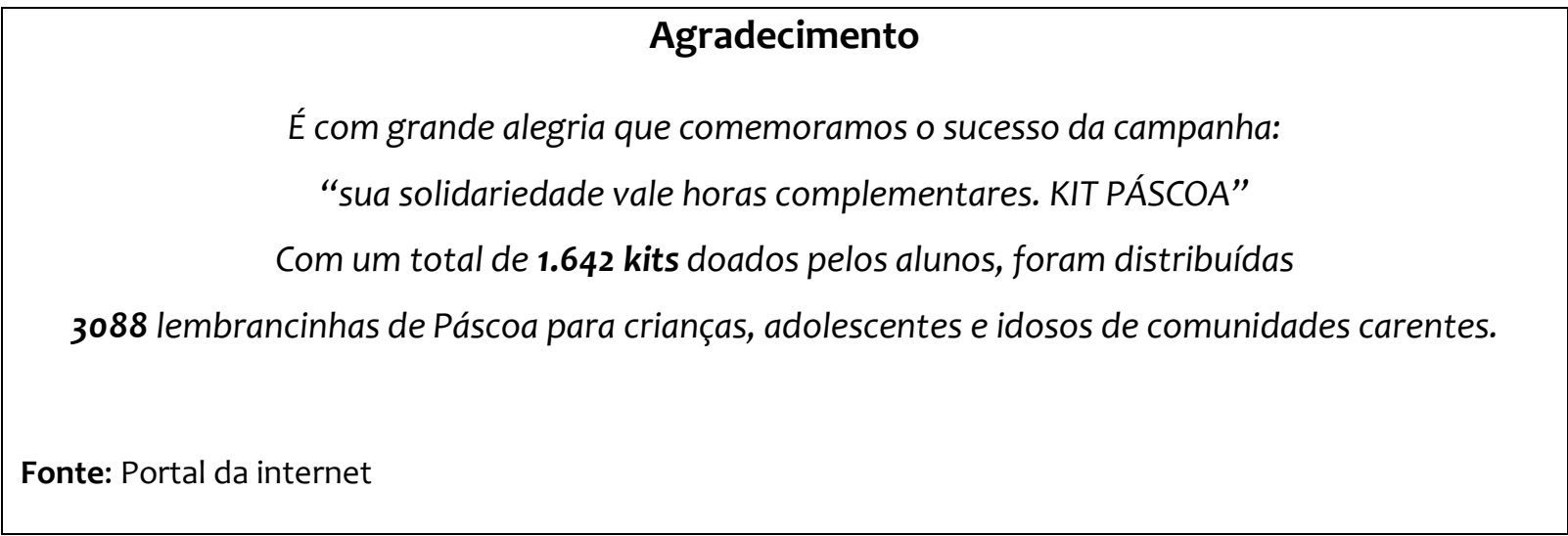

O mais interessante das mensagens é o esforço para naturalizar a relação entre serviço voluntário e interesses pessoais. As diversas ações formuladas projetam uma cultura de solidariedade em que um ato somente pode ser feito em troca de outro. A nova significação dessa ação humana também se amarra a jogos de interesses. De fato, parece que de uma hora para outra todos se sentem comprometidos com a responsabilidade social e o desenvolvimento sustentável. Em tempos de neoliberalismo, a relação com o próximo e com o ambiente tornou-se um negócio, mais uma commodity (BAUMAN, 2008).

Como nos faz crer Foucault (2008), a lógica neoliberal transformou ações sociais diversas em ações inseridas e planejadas sob a lógica da grade econômica. No caso, uma atividade comunitária atrelada à troca por horas complementares, que deveriam estimular outras modalidades em que conhecimentos não acadêmicos são prestigiados, é mais uma estratégia de controle político sobre a identidade do sujeito. Uma atividade que fornece condições para normalizar e, assim, naturalizar a ação comunitária-solidáriaresponsável e as trocas econômicas. Essa prática, por regular comportamentos, produz os sujeitos desejados, sejam gestores ou alunos. Eles se inserem em "novas distribuições funcionais e graduais/hierárquicas de responsabilidades" (DALE, 2002, apud BALL, 2004, p.1106). Desse modo, os resultados da coleta apagam suas teias de saber/poder e legitimam o discurso da responsabilidade socioambiental, enaltecendo sujeitos colaboradores e a instituição organizadora. As bondades sociais realizadas por ações institucionais reforçam o casamento do neoliberalismo com o Ensino Superior. 
A onda verde e voluntária está minimamente articulada com as novas formas de governo das populações. Trata-se de mais um movimento que caracteriza a nova ordem empresarial, cujo propósito é manter a hegemonia do pensamento capitalista. A assistência aos desafortunados pode ser compreendida como conjunto de práticas que tem como objetivo atenuar (ou superar) não só o déficit material, mas, principalmente, a moral dos necessitados de uma sociedade (FONTES, 2005). A assistência é gerada no interior da sociedade e, desde a Revolução Industrial, é consequência da sua estruturação em classes sociais. Em todas as épocas, ela teve como objetivo manter a coesão social de seus membros. E isso não é diferente em tempos de risco de fragmentação da sociedade, nos quais é necessário assegurar as condições de reprodução da força de trabalho a fim de aumentar a produtividade para que os diversos nichos sociais possam ter a sua disposição o que consumir.

A onda de mudanças nos anos 1990 não alcançou somente a educação. A seguridade social também foi atingida. Frente à redução dos gastos com essa área, criaram-se novas estratégias para combater as consequências do modo de produção capitalista, ainda mais aprofundadas pela globalização e pelo neoliberalismo.

A responsabilidade social empresarial parece ser a resposta para esse dilema. $O$ conceito emerge na mesma década como a nova estratégia da assistência em uma sociedade na qual as entidades empresariais assumem um caráter relevante. $\mathrm{O}$ aumento da concorrência, intensificado com a entrada de investidores estrangeiros no Brasil, fez com que a prática ganhasse força diante das novas formas de gestão e relacionamento das empresas com seus potenciais consumidores. Como resultado, as entidades privadas assumiram o discurso da solidariedade com uma roupagem de voluntariado. Em um país marcado pela desigualdade, em um momento que o mundo reclama contra o processo de devastação ambiental causado pela exploração econômica, a preocupação das empresas passou a ser a promoção de uma economia solidária, isto é, a criação de vínculos entre questões econômicas e coesão social: o propalado discurso do desenvolvimento sustentável. Surge a busca pelo selo de qualidade socioambiental. Com crescentes investimentos, os empresários estão vinculando sua ação social a várias áreas além da educacional e assistencial. Áreas de cultura, meio ambiente, esportes e lazer também se 
transformaram em alvos. Nesse contexto, cada vez mais se criam fundações, institutos e departamentos dentro das próprias empresas voltados para a sistematização dessas ações (FONTES, 2005). A consolidação do projeto depende de uma atuação correspondente da população. Para tanto, torna-se imprescindível educar os sujeitos com o mesmo propósito.

Para Fontes, a responsabilidade social somente dá retorno à empresa mediante ações mais contundentes, como desenvolver projetos sociais interligados com instituições comunitárias, escolas, postos de saúde, centros de esporte e outros, envolvendo-se em todos os acontecimentos da comunidade, apoiando eventos e o comércio local, emprestando suas instalações em benefício de programas comunitários como encontros, aulas e eventos de grupos e organizações sem fins lucrativos. Tais ações não representam grande ônus financeiro, mas são fundamentais para a imagem da empresa. Ser socialmente responsável tornou-se um dos pilares de sustentação dos negócios, tão importante como a qualidade, a tecnologia e a capacidade de inovação. Sem contar que é preciso manter o controle das populações, logo, da coesão social, para a manutenção das bases de produção e acúmulo de capital sem interferências do Estado.

É importante lembrar que muitas empresas perguntam em seus questionários de contratação quanto tempo o sujeito interessado pelo cargo disponibiliza para ações voluntárias e exigem experiência nessa prática social. A instituição investigada, além de fornecer e valorizar essa posição de sujeito, também prepara e adapta seu aluno-cliente para as particularidades do mercado de trabalho. Em suma, a condição referente à responsabilidade social pode ser mais uma forma de comodificação do sujeito universitário, pois nas relações de mercado:

Nem o vendedor nem o comprador precisam ser impelidos pela boa vontade ou pelo amor ao próximo ou pela solidariedade para alcançar o sucesso no jogo do mercado. Na verdade, o mercado funciona melhor se cada parte da transação consultar exclusivamente seu próprio interesse. (HALL, 2003, p. 276)

... e o interesse está cada vez mais em expor, produzir e fazer a si mesmo. 
A atual governamentalização do Estado neoliberal sustenta as políticas de reforma do setor público, inclusive a Educação Básica e Superior. Para Ball (2006), os efeitos de mercado nessas reformas estão enraizados em uma psicologia social do autointeresse, nos ensinando a respeitar resultados e não princípios. Consequentemente, os novos mercados sociais são definidos por uma mistura de incentivos e recompensas que estimulam respostas autointeressadas. A economia de mercado neoliberal apoia-se nas concepções que afirmam a competição como algo natural, sendo a humanidade composta de indivíduos cuja referência de ser é basicamente o si mesmo. O mercado dá apenas um impulso. Segundo Ball, essas reformas criam um novo ambiente moral, tanto para o consumidor quanto para o produtor, introduzindo ambos em uma "cultura dos interesses do self". O mercado realça a ética de interesses e desejos pessoais e, ao mesmo tempo, obscurece e deprecia o discurso da igualdade ancorado no ponto de vista impessoal. Ao fim e ao cabo, o sujeito do neoliberalismo é objetivado para agir dentro da lógica do interesse pessoal.

No entanto, esse sujeito de uma sociedade individualizada precisa se inserir no contexto de uma sociedade globalizada. É necessária a aprendizagem do ideal de comunidade. Sendo que essa comunidade é constituída em condições históricas específicas em meio aos interesses políticos que a regulam (ANDERSON, 2008). No atual cenário da comunidade global, cuidar do Outro e do ambiente pode se tornar um sentimento de afiliação e atributo comum, ocasionando novas formas de identificação para o sujeito atuar no espaço público de forma aceitável sem que isso possa interferir nos seus interesses pessoais.

Ainda há mais. No jogo da individualização dos sujeitos, a sua autonomia consiste em fazer com que ele se encarregue de seu rumo e arque com suas consequências. É por aqui que ganha força o discurso "fazer a diferença". Ação que pode se tornar em uma estratégia de desmobilização social quanto às reivindicações populares para que o Estado cumpra seu dever no que tange às garantias dos direitos sociais aos seus cidadãos. Os projetos sociais podem ser vistos como uma forma de responsabilização compartilhada que se opõe às formas tuteladas pelo Estado. Ou seja, conforme se observa, o Ensino 
Superior privado contribui para subjetivar seus sujeitos em acordo com as mudanças globais.

Nessa estratégia de governo das populações, as concepções morais de esfera pública são pauperizadas. Planejar com vistas ao bem comum e com foco na esfera pública torna-se uma ação sem sentido. É nesse cenário que o Estado gasta menos com o controle da população ao mesmo tempo em que pode regular mais as ações de seus sujeitos. Em contrapartida, afrouxa a regulação do mercado em ações de exploração da mão de obra e recursos naturais. Por aqui, o sujeito é interpelado a participar dos programas de desenvolvimento sustentável, não como um processo de escolha voluntária, mas com a obrigação de contribuir para o equilíbrio do capitalismo globalizado, no qual seus interesses também estão em jogo.

Carregados por essa maré, os projetos sociais da instituição não param. Acompanham o crescimento da marca e consolidam o Ensino Superior como espaço de oferta de serviços que tradicionalmente competem ao poder público. Desde dezembro de 2008, a instituição presta serviços em assessoria administrativa, pedagógica e social a uma creche que atende crianças em estado de abandono familiar. Na área de Educação e Cultura, os projetos desenvolvidos voltam-se para jogos e brincadeiras, música, narração de histórias, alfabetização, artes visuais, inclusão digital, artesanato, teatro e arte culinária.

$\mathrm{Na}$ área de Educação e Cidadania, as propostas desenvolvidas referem-se à conscientização de direitos para os membros das comunidades atendidas; à valorização da terceira idade e assistência ao idoso; organização de bazar para angariar fundos; promoção de eventos para o fortalecimento do vínculo afetivo entre crianças e seus familiares; organização de palestras sobre a inclusão de pessoas com deficiência física e intelectual. Comumente, os projetos mencionados são alocados em escolas públicas, ONGs, associações de bairro, abrigos para crianças, igrejas, hospitais e no próprio campus da instituição.

A área da Saúde mantém uma clínica-escola de Fisioterapia que promove o atendimento gratuito às pessoas da comunidade, além de campanhas preventivas ou de 
doação de sangue, entre elas: propostas voltadas à promoção da saúde por meio de exercícios físicos, à prevenção de doenças sexualmente transmissíveis e à gravidez na adolescência; programas de orientação de aleitamento materno e palestras educativas visando o combate ao mosquito transmissor da dengue. Há alguns anos, a área realizou uma "caravana da saúde" envolvendo alunos dos cursos de Educação Física, Enfermagem e Fisioterapia, juntamente com o Comando de Policiamento de Área Metropolitana da Região Sul de São Paulo. O evento aconteceu em uma escola pública situada em um bairro desassistido politicamente e englobou palestras, orientações sobre saúde, testes de glicemia capilar e aferição de pressão arterial. Também foi realizado um projeto em parceria com a Polícia Militar que objetivou o desenvolvimento de ações voltadas à integridade física das pessoas, valorizando as campanhas de combate à violência e criação de uma "Cultura de Paz".

Na área da Educação Física, reiteradamente alguns professores e a coordenação enfatizam a intenção de implantação de escolinhas de esporte, atividades rítmicas e acrobáticas, ginástica laboral para ofertar à comunidade. Já se veiculou a intenção de realizar campanhas de promoção de atividades físicas para grupos da terceira idade ou em postos de saúde e Casas de Cultura. Em funcionamento, constata-se a prática de exercícios físicos pelos professores, funcionários e colaboradores diretos interessados em dois horários da academia-escola entre o final das aulas da manhã e início do vespertino, e ao entardecer, entre o final das aulas do vespertino e início do noturno. As atividades são organizadas por dois professores do curso de Educação Física, auxiliados por estagiários. A piscina do campus é alocada por uma pessoa alheia à instituição, mas as aulas e treinamentos oferecidos à comunidade são ministrados por estudantes.

Todas as ações são realçadas e valorizadas nas reuniões gerais do coletivo docente e divulgadas à comunidade educativa pela internet. Elas reforçam o novo marco de administração contemporânea e podem ser compreendidas enquanto estratégias que fortalecem o novo gerencialismo como uma das bases do neoliberalismo.

Para Peters, Marshall e Fitzsimons (2004), a transferência da gestão dos serviços de assistência social para o setor privado representa a introdução de um corpo estranho ideológico em um setor tradicionalmente avesso ao pensamento assistencial. Apesar 
disso, para os autores, os discursos neoliberais de governança são potentes e se estabelecem por conta da sua capacidade de articular a economia, o social e a política em nome da escolha racional como princípio de legitimidade. Ou seja, as ações institucionais citadas revelam plena sintonia com os pressupostos da responsabilidade socioambiental, contribuindo para que a formação no Ensino Superior leve cada sujeito a: assimilar a importância de prover aquele que se encontra em situação de abandono social; cuidar do meio ambiente; adquirir noções hegemônicas de saúde e socialização e valorizar a função voluntária como parceira-chave da responsabilidade social empresarial.

\section{Considerações}

Em tempos de reestruturação do Estado e do seu descaso com o bem-estarsocial, da falência forçada de suas funções liberais revolucionárias ou da sua recontextualização em tempos pós-modernos e transnacionais, a instituição que acolheu a pesquisa faz seu papel. Reforça os discursos e práticas que enaltecem as transformações da sociedade e a criação do Pós-Estado da Providência que nos fala Ball (2004).

Pode-se afirmar que as ações desenvolvidas na instituição são utilizadas de forma genérica e coadunam-se com a ordem social vigente. Nesta, valorizam-se os conceitos que se aproximam da ideia do cuidar do próximo e do meio ambiente, atendendo expectativas pessoais, tanto daqueles que se preocupam com questões socioambientais, quanto daqueles que estão centrados nas questões mercadológicas. Atender aos apelos do voluntariado parece ser uma atividade profundamente articulada ao governo de si mesmo e das populações, pois se comportar dessa maneira está aprovado dentro das condições sociais e históricas atuais.

Não foi o objetivo deste texto apresentar um aprofundamento acerca da “relação dialética ente o local e o global” (GIDDENS, 2002), entre as comunidades contempladas pelas ações sociais e a instituição, entre os modos que os indivíduos envolvidos organizam ativamente suas relações entre si e entre eles e outras influências provenientes do sistema social mais amplo. Tampouco, foi intenção debater o papel das 
agências do Terceiro Setor nessa esfera social, muito menos as ações desenvolvidas pela instituição. O que se pretendeu foi apenas lançar um alerta para possíveis formas de subjetivação, visto que as ações da instituição são reforçadas junto aos estudantes em diversos tempos e espaços. Mediante uma sofisticada parafernália de estratégias de divulgação, as ações desenvolvidas contam com uma grande adesão. Os discursos recorrentes apoiam-se em técnicas que funcionam como vontade de verdade que exerce “uma espécie de pressão e como que um poder de coerção" (FOUCAULT, 2006, p. 18). Isso fica mais explícito quando se observa a quase obrigatoriedade para que os sujeitos realizem ações voluntárias.

Por sua vez, os projetos realizados em espaços sociais denominados carentes, em verdade, são marcados como autoinsuficientes ou produtos do abandono social. Isso reforça os discursos vinculados à ineficiência do Estado, à necessidade da atuação do Terceiro Setor e ao recrudescimento de políticas de compensação cultural. São esses os discursos que validam a atuação do empresariado nos programas de assistência social, realizados mediante a troca por isenções concedidas pelo Estado e consolidados pela participação autointeressada dos alunos-clientes. Cabe ressaltar que essas políticas reforçam o policiamento do território e da população e são consolidadas, muitas vezes, por ações executadas (nem sempre planejadas) pelos mesmos representantes das populações localizadas, que neste caso são alunos da instituição.

A análise da trama produzida pela IES possibilita dizer que as localidades não conseguem mais determinar e gerar seus sentidos e ficam cada vez mais à mercê de ações exteriores/globais que atribuem sentidos às suas vidas, criando formas de regulação e imobilização (BAUMAN, 1999). Como coloca Lipovetsky (2012), a ambivalência dos meios e das técnicas produzidas pela globalização tem produzido também a ambiguidade das ações e dos sentimentos dos sujeitos destes tempos. 


\section{Referências}

ANDERSON, BENEDICT Comunidades imaginadas: reflexões sobre a origem e a difusão do nacionalismo. São Paulo: Companhia das Letras, 2008.

BALL, STHEPEN. Reformar escolas/ reformar professores e os terrores da performatividade. Revista Portuguesa de Educação. Minho, v. 15, n. 02, p. 3-23, 2002.

BALL, STHEPEN. Performatividade, privatização e o pós-Estado do bem-estar. Dossiê: Globalização e Educação: precarização do trabalho docente - II. Educação e Sociedade, Campinas, v. 25, n. 89, p. 1105-1126, set/dez. 2004.

BALL, STHEPEN. Sociologia das políticas educacionais e pesquisa crítico-social: uma revisão pessoal das políticas educacionais e da pesquisa em política educacional. Currículo sem fronteiras, v. 6, n.2, p.10-32, Jul./Dez. 2006.

BAUMAN, ZIGMUNT. Globalização: as consequências humanas. Rio de Janeiro: Jorge Zahar Editora, 1999.

BAUMAN, ZIGMUNT. Vidas para o consumo. Rio de Janeiro: Jorge Zahar Editora, 2008.

BAUMAN, ZIGMUNT. Capitalismo parasitário. Rio de Janeiro: Jorge Zahar Editora, 2010.

BURBULES, NICHOLAS; TORRES, CARLOS ALBERTO. Introdução. In: BURBULES, NICHOLAS; TORRES, CARLOS ALBERTO. (Orgs.). Globalização e educação: perspectivas críticas. Porto Alegre: Artmed, 2004.

FONTES, ANDREA SOUZA. A responsabilidade social em questão: o pensamento pedagógico do Instituto Ethos. Trabalho Necessário, Niterói, ano 3, n. 3, 2005, p. 00-0o

FOUCAULT, MICHEL. A ordem do discurso. São Paulo: Loyola, 2006.

FOUCAULT, MICHEL. O nascimento da biopolítica. São Paulo: Martins Fontes, 2008.

GIDDENS, ANTHONY. Modernidade e identidade. Rio de Janeiro: Jorge Zahar Editora. 2002.

HALL, STUART. Da Diáspora: identidades e mediações culturais. Belo Horizonte: Editora UFMG, Brasília: Representações da Unesco no Brasil, 2003.

HALL, STUART. A Centralidade da cultura: notas sobre as revoluções de nosso tempo. Educação e Realidade. Porto Alegre, v. 22, n. 2, p. 15-46, 1997. 
LIPOVETSKY, GILLES. O reino da hipercultura: cosmopolitismo e civilização ocidental. In: JUVIN, HENRY; LIPOVETSKY, GILLES. A globalização ocidental: controvérsias sobre cultura planetária. Barueri, SP: Manole, 2012.

PETERS, MICHEL; MARSHALL, JAMES; FITZSIMONS, PATRICK. Gerencialismo e política educacional em um contexto global: Foucault, neoliberalismo e a doutrina da autoalimentação. In: BURBULES, N.; TORRES, C. A. (orgs.). Globalização e educação: perspectivas críticas. Porto Alegre: Artmed, 2004.

POPKEWITZ, THOMAS. A reforma como administração social da criança: a globalização do conhecimento e do poder. In: BURBULES, NICHOLAS; TORRES, CARLOS ALBERTO (orgs.). Globalização e Educação: perspectivas críticas. Porto Alegre: Artmed, 2004.

VEIGA-NETO, ALFREDO. Educação e governamentalidade neoliberal: novos dispositivos, novas subjetividades. In: PORTOCARRERO, VERA; CASTELO BRANCO, GUILHERME. (orgs.) Retratos de Foucault. Rio de Janeiro: Nau, 2000. 